\title{
A Smart Two-Stage Charging Strategy Implemented on a PV Module Array with a Simple MPPT for $\mathrm{LiFePO}_{4}$ Batteries
}

\author{
Pi-Yun Chen, Kuei-Hsiang Chao * and Yu-Sheng Tsai \\ Department of Electrical Engineering, National Chin-Yi University of Technology, No.57, Sec. 2, Zhongshan Rd., \\ Taiping Dist., Taichung 41170, Taiwan; chenby@ncut.edu.tw (P.-Y.C); tsaiyu543@gmail.com (Y.-S.T) \\ * Correspondence: chaokh@ncut.edu.tw; Tel.: +886-4-29324505\#7272
}

\begin{abstract}
This paper aims to present a smart high speed battery charger, powered by a photovoltaic module array, for a $\mathrm{LiFePO}_{4}$ battery as a solar energy storage device. With a battery charging strategy, the presented battery charger involves a Buck converter as the core equipped with a simple maximum power point (MPP) tracker. Considering complexity reduction and easy hardware implementation, a constant voltage MPP tracking approach is adopted such that the maximum amount of output power can be delivered to the load in response to an arbitrary change in the solar radiation. A smart two-stage charging strategy, with a constant current mode followed by a constant voltage mode, is employed in such a way that the battery charge process can be accelerated largely, while the damage caused by overcharging can be prevented. In the end, the performance of this proposal is validated experimentally.
\end{abstract}

Keywords: battery charger; photovoltaic module array; $\mathrm{LiFePO}_{4}$ battery; Buck converter; maximum power point tracker; smart two-stage charging strategy.

\section{Introduction}

There is a rapid rise in electricity price as a consequence of the upcoming global oil crisis, and the search for and the development of alterative and particularly green energy sources turns into a critical issue. Solar energy has been long seen as a promising candidate to resolve the threat of oil crisis, but a disadvantage is that the generated solar power cannot be well regulated due to a number of factors, e.g. time-varying solar radiation, climate uncertainty, etc. Hence, it is a significant and urgent issue to improve the performance of solar power generators in practical uses [1].

As a reusable electric device, secondary batteries continue to gain worldwide attention due to the global warming and eco-friendly concerns. In an attempt to reduce the amount of $\mathrm{CO}_{2}$ emission, a great number of research institutes and business concerns have made continuous efforts to search for alternative energy sources, such as solar power, wind power, fuel cell, and more, or to the improvement in the conversion of secondary batteries. There is no doubt that Li-ion batteries will gradually take the place of lead-acid and Ni-hydrogen batteries in the long term, and particularly $\mathrm{LiFePO}_{4}$ batteries ranks the first place among a wide variety of Li-ion batteries due to their high capacity and long service time [2]. Besides, a $\mathrm{LiFePO}_{4}$ battery does not require a high current charger, meaning that it can be charged by a solar powered battery charger even at low levels of solar radiation.

The output power of a photovoltaic module is known as a function of solar radiation, module temperature, etc. Due to efficiency concern, the MPP is tracked by a constant voltage MPP tracking approach herein so as to transfer the maximum amount of power at all events to a $\mathrm{LiFePO}_{4}$ battery through the presented battery charger. A two-stage charging strategy is employed in such a way that the charger works in constant current mode to speed up the charge process of a high capacity $\mathrm{LiFePO}_{4}$ battery, and then operates in constant voltage mode so as to keep the battery voltage below 
the evaporation voltage for safety concern. In this manner, the aim of efficiency improvement, charge process acceleration and an extended battery life is hence achieved.

For performance testing of this presented two-stage battery charging strategy, high current charge/discharge characteristic curves of a $\mathrm{LiFePO}_{4}$, i.e. plots of the battery voltage, current and state of charge against time, are made for behavioural analysis of batteries.

\section{Solar Cell}

\subsection{Solar Cell Basics}

A solar cell is a semiconductor device. Over the electrically neutral PN region, electron-hole pairs are generated as a consequence of incident solar energy. Due to the influence of the electric field across the depletion region, electrons and holes drift across the P-N junction toward the $\mathrm{N}$ and $\mathrm{P}$ regions, respectively. Illustrated in Figure 1 is a mathematic model of a solar cell, where $I_{p h}$ represents the short-circuit current at a given level of solar radiation, and $R_{s}$ the contact resistance between the metal electrodes and the semiconductor material.

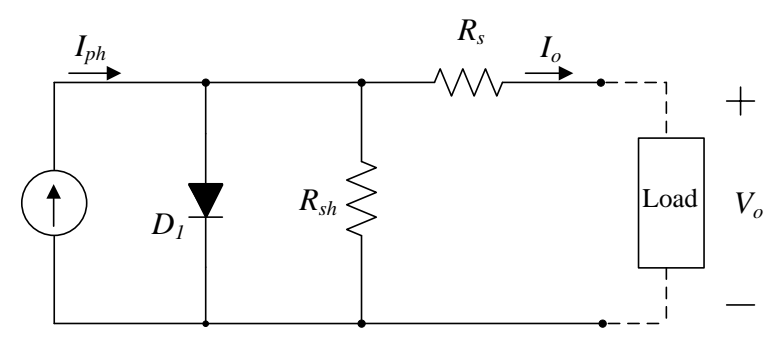

Figure 1. Circuit model of a photovoltaic cell.

The output current $I_{o}$, provided by a solar cell, is given as

$$
I_{o}=I_{p h}-I_{s a t}\left[\exp \left(\frac{q\left(V_{O}+I_{O} R_{S}\right)}{A K T}\right)-1\right]-\frac{V_{O}+I_{O} R_{S}}{R_{S h}}
$$

where $I_{p h}$ represents the short-circuit current at a given solar radiation,

$I_{\text {sat }}$ the reverse saturation current of the diode $D_{1}$,

$q=1.6 \times 10^{-19} \mathrm{C}$ the charge carried by a single electron,

$V_{o}$ the output voltage of the solar cell,

$A=1-2$ the dielectric constant,

$K=1.3806505 \times 10^{-23} \mathrm{JK}^{-1}$ the Boltzmann constant,

$R_{s h}$ the equivalent shunt resistance,

$R_{s}$ the equivalent series resistance, and

$T=25^{\circ} \mathrm{C}(298 \mathrm{~K})$ the surface temperature of the solar cell.

\subsection{MPP Tracking Strategies for a PV Module Array}

It is known that the performance of a PV module array and MPPs demonstrate a strong dependence on exterior factors, e.g. solar radiation, temperature, etc. In consideration of efficiency optimization, an MPP tracker is employed to deliver the maximum amount of solar power to the load. Up to now, there have been a great volume of published studies on this issue [3,4], among which the constant voltage, power feedback, perturb and observe, incremental conductance methods, and so on, are the most commonly seen approaches, and the constant voltage method is demonstrated as the easiest and simplest way to perform a tracking task. The idea is to make a PV module array work at a specific output voltage. Illustrated in Figure 2 is a one-parameter family of $\mathrm{I}-\mathrm{V}$ characteristic curves. As revealed, the MPP voltage demonstrates little dependence on the level of solar radiation. In simple terms, the design complexity of an MPP tracker can be reduced 
considerably, provided that the tracker is operated at the maximum power voltage specified in the datasheet thereof. On account of high reliability, stability and low cost, the constant voltage MPP tracking approach is employed herein.

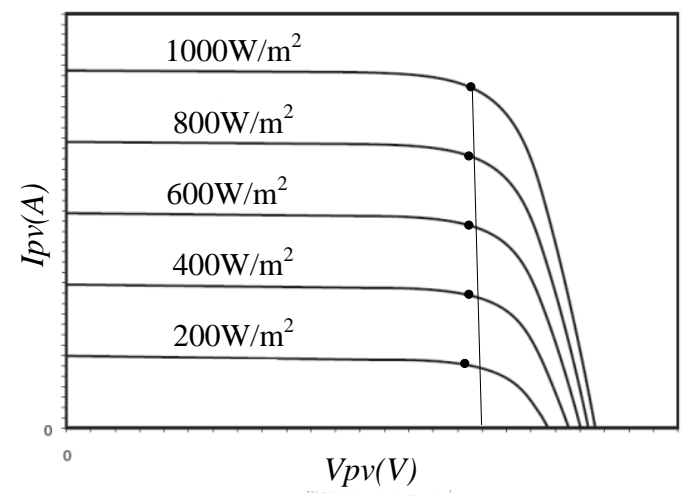

Figure 2. A family of I-V characteristic curves of a PV module array with the solar radiation level as a parameter.

\section{PIC Microcontroller}

PIC series microcontrollers, including 8, 16 and 32-bit, are provided by Microchip Technology Inc. [5]. As the controller core, a PIC18F8720 microcontroller [6] is employed with the underlying key features:

(1) a high performance Reduced Instruction Set Computing (RISC) CPU,

(2) linear program memory addressing to 128 Kbytes, linear data memory addressing to 3840 bytes, 1 Kbyte of data EEPROM, up to $10 \mathrm{MIPs}$ operation, DC - $40 \mathrm{MHz}$ osc./clock input with PLL active,

(3) 16-bit external memory interface, address capability of up to 2 Mbytes,

(4) high current sink/source $25 \mathrm{~mA} / 25 \mathrm{~mA}$,

(5) four external interrupt pins,

(6) five Capture/Compare/PWM (CCP) modules,

(7) programmable 16-level Low Voltage Detection (LVD) module, and

(8) 10-bit, up to 16-channel Analog-to-Digital Converter (A/D)

\section{Charge/Discharge Characteristics of a Li-Iron Battery}

\subsection{Li-Iron Battery Survey}

Among a wide range of secondary batteries, lithium ion, particularly Li-iron [7], batteries gain wide popularity in practical applications due to the advantages of high energy density, high discharge voltage, low self discharge rate, no memory effect and long battery life. $\mathrm{LiFePO}_{4}$ battery, Li-iron battery for short, are proposed in 1997 by Padhi et al. [8-10] with $\mathrm{LiFePO}_{4}$ as positive electrode materials. In contrast to conventional $\mathrm{LiMn}_{2} \mathrm{O}_{4}, \mathrm{LiNiO}_{2}$ and $\mathrm{LiCoO}_{2}$ batteries, a $\mathrm{LiFePO}_{4}$ battery does not contain any precious metals, e.g. $\mathrm{Mn}, \mathrm{Ni}, \mathrm{Co}$, and hence acquires a cost advantage. Besides, it is a high safety, high capacity and an eco-friendly energy storage device.

As opposed to inherently unsafe $\mathrm{LiCoO}_{2}$ batteries, there exists a strong covalent bond between molecules of positive electrode materials in a $\mathrm{LiFePO}_{4}$ battery. For this sake, the risk of explosion and flame is completely removed during the use of $\mathrm{LiFePO}_{4}$ batteries, a clear advantage over other types of batteries. Moreover, $\mathrm{LiFePO}_{4}$ batteries serve as a high performance energy storage device, since the requirement of high capacity, zero pollution, low self discharge rate, long service life (the number of discharge and charge cycles), high coulombic efficiency, light weight and high safety, etc, can be fulfilled. Furthermore, it features high current charge/discharge.

Accordingly, a 48V 10Ah EA-480100-C15 $\mathrm{LiFePO}_{4}$ battery is employed as an energy storage device for the presented photovoltaic system. The specifications of the Li-iron battery are given in Table 1. 
Table 1. LiFePO4 battery specifications.

\begin{tabular}{cc}
\hline Name & EA-480100-C15 \\
Rated capacity & $10 \mathrm{Ah}$ \\
Rated voltage & $52.8 \mathrm{~V}$ \\
Charging cutoff voltage & $58.4 \mathrm{~V}$ \\
Discharging cutoff voltage & $45.6 \mathrm{~V}$ \\
Maximum charge current & $10 \mathrm{~A}$ \\
Temperature range of charging & $0 \sim 60^{\circ} \mathrm{C}$ \\
Temperature range of discharging & $-20 \sim 70^{\circ} \mathrm{C}$ \\
\hline
\end{tabular}

\subsection{PIC Microcontroller Charging Strategies for Li-Iron Batteries}

PIC series microcontrollers, including 8, 16 and 32-bit, are provided by Microchip Technology Inc. [5]. As the controller core, a PIC18F8720 microcontroller [6] is employed with the underlying key features: The way to charge a battery is found to demonstrate significant influence on the service life of the battery. Hence, recommended battery charge strategy can be found in an official guide provided by each battery manufacturer. Yet, it takes a relatively long time span to charge a battery, namely a slow paced charge strategy due to safety concerns. Nonetheless, high performance charge strategies become a key issue in the development of battery chargers in an attempt to meet the cost reduction requirement in today's highly competitive market. Batteries are characterized in official user guides in terms of Cut-off Voltage, Charge Voltage, Maximum Charge Current, Maximum Continuous Discharge Current, and more. Hence, a high performance battery charger must be developed in compliance with the specifications.

As stated in [11], there are up to 5 ways to charge a lithium-iron battery as a rule. The battery charging strategy employed herein is a two-stage approach, namely, a constant current mode followed by a constant voltage one, and benefits from both charging modes. In this fashion, the charge time can be reduced considerably when operated in the constant current mode, while the service life of a battery can be well maintained when in the constant voltage mode. During the first stage of a charging process, the battery charger works in constant current mode for efficiency concern. When the battery output voltage approaches a specified threshold, the charger switches to the constant voltage mode to protect the battery from overcharging. The charging process continues until the voltage threshold is reached.

Presented in Figure 3 is an illustration of a two-stage battery charging approach. The first stage is the so-called bulk charge step, since a high speed battery charging is performed by a charger operating in constant current mode. The process proceeds until a voltage threshold is reached. At this point in time, the battery is not fully charged, not a 100\% state of charge (SOC). Hence, the charging process moves into the second stage, that is, the constant voltage mode. Over the second stage, the charge current falls steeply, but the battery voltage rises smoothly, with time, until another voltage threshold (a 100\% SOC) is reached.

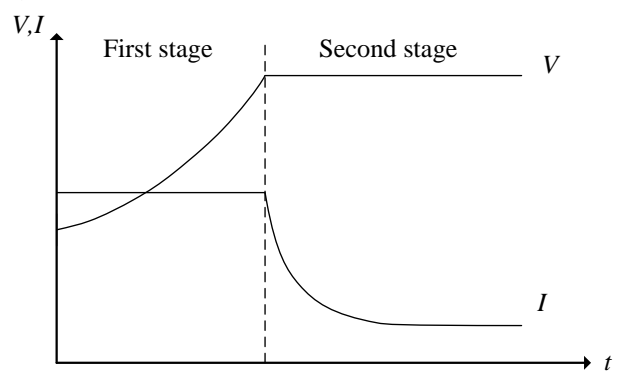

Figure 3. A schematic of a two-stage battery charging strategy. 


\section{Li-Iron Batteries as Solar Energy Storage Devices}

\subsection{Step-Down DC-DC Converter}

In terms of circuit configuration, non isolated DC-DC converters can be categorized into Buck Boost, Buck-Boost, Ćuk, SEPIC and Zeta converters, etc [12]. A Buck converter is employed herein due to the advantage of easy hardware implementation. Sketched in Figure 4 is the framework of a Buck converter, also known as a voltage step-down converter, since the converter's output voltage is kept below the input at all events.

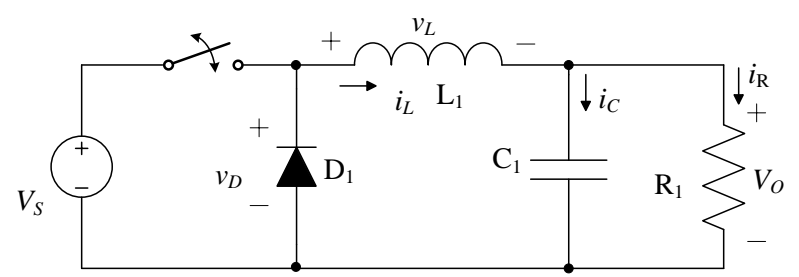

Figure 4. Framework of a Buck converter.

According to the volt-second balance, the input and output voltage are related by [12]

$$
V_{o}=V_{S} D
$$

\subsection{Battery Charger Framework}

Demonstrated in Figure 5 is a schematic diagram of the presented Li-iron battery charger, i.e. mainly a Buck converter composed of an inductor $L_{1}$, a capacitor $C_{1}$, a high speed switching diode $D_{1}$ and an IGBT transistor $S W_{1}$. Through a skillful manipulation of the duty cycle $D$ in the buck converter, an MPP is tracked and the PV module array serves as a battery charger. The output voltage of a voltage divider formed of the resistors $R_{3}, R_{4}$ and the current sensed by a current sensor are fed into a microcontroller, and then the battery output voltage $V_{B}$ and current $i_{B}$ are evaluated through the built-in ADCs. According to the detected voltage level, the battery charger is operated in the preset mode.

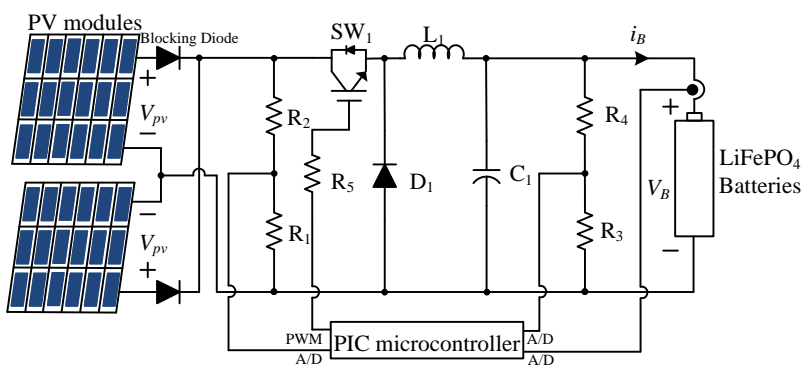

Figure 5. Framework of the presented battery charger controller.

In case the charge current falls below a specified level due to an insufficient supply of solar radiation, the MPP tracker is enabled for efficiency improvement. As the first step, a fraction of the PV module output voltage is fed into the microcontroller through a voltage divider consisting of resistors $R_{1}, R_{2}$, and then the PV module output voltage is found by means of a built-in ADC. Subsequently, an MPP tracking task is performed by regulating the PV module output voltage at the specified maximum power voltage on a condition that the battery voltage lies below $58 \mathrm{~V}$, as illustrated in Figure 6. 


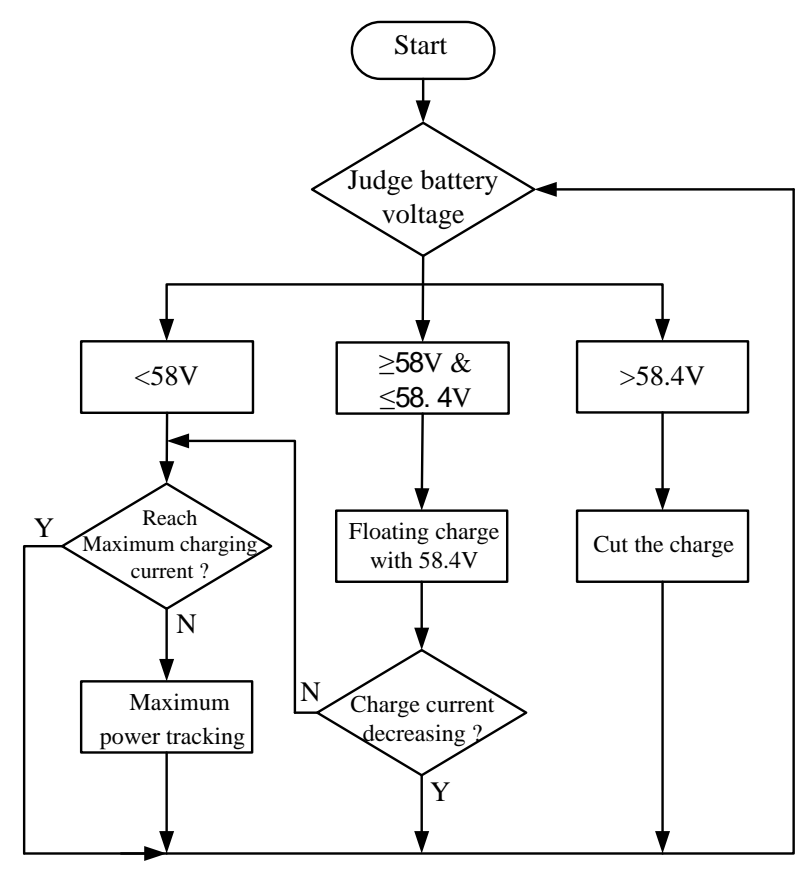

Figure 6. Control flow chart of the presented battery charger.

\section{3. $\mathrm{LiFePO}_{4}$ Battery Charger Design}

\subsubsection{PV module specifications}

Table 2 gives the electric specifications of a Kyocera KC40T photovoltaic module [13], according to which the presented battery charger is designed.

Table 2. LiFePO4 battery specifications.

\begin{tabular}{cc}
\multicolumn{2}{c}{ Type : KC40T } \\
\hline Maximum output power & $43 \mathrm{~W}$ \\
Current of maximum power point & $2.48 \mathrm{~A}$ \\
Voltage of maximum power point & $17.4 \mathrm{~V}$ \\
Open voltage & $21.7 \mathrm{~V}$ \\
Short current & $2.65 \mathrm{~A}$ \\
\hline
\end{tabular}

As tabulated in Table 2, a Kyocera KC40T PV module provides an MPP output current of $2.48 \mathrm{~A}$ approximately. Hence, as many as $12 \mathrm{PV}$ modules are cascaded as a high speed battery charger to deliver a maximum output power of $516 \mathrm{~W}$ approximately toward an EA-480100-C15 $\mathrm{LiFePO}_{4}$ battery.

The battery charger is designed to operate only when the output voltage $V_{P V}$ of the PV module array lies between 62 and $208 \mathrm{~V}$ with a maximum charge current $i_{B}$ of $10 \mathrm{~A}$. The charge process continues in case the battery output voltage $V_{B}$ lies beyond $58 \mathrm{~V}$ and below $58.4 \mathrm{~V}$. According to Equation (2), the duty cycle $D$ of the Buck converter, illustrated in Figure 5, is bounded by

$$
D_{\min }(=0.21) \leq D \leq D_{\max }(=0.95)
$$

And the load resistance $R_{L}$ is given as

$$
R_{L}=\frac{V_{B}}{i_{B}}=\frac{58.4}{10}=5.84(\Omega)
$$




\subsubsection{Component choices}

Tabulated in Table 3 are the component choices for the presented Li-iron battery charger [12].

Table 3. Component choices for the employed Buck converter.

\begin{tabular}{cc}
\hline Part & Specification and model \\
\hline Inductor & $120 \mu \mathrm{H} /$ AWG16\# \\
Capcitor & $33 \mu \mathrm{F} / 100 \mathrm{~V}$ \\
Semiconductor switch & G4PH50UD /50A, 1200V \\
Diode & $40 \mathrm{EPF} 06 / 40 \mathrm{~A}, 600 \mathrm{~V}$ \\
\hline
\end{tabular}

\subsection{Measurements}

Presented in Figure 7 is a photo of the implemented charge controller, programmed in C language, with a PIC18F8720 chip as the core. In consideration of measurement efficiency improvement, a PVS0120 PV simulator [14] is employed to simulate the performance of an array of Kyocera KC40T PV modules, as specified in Table 2, and to conduct an MPPT performance test at various irradiation levels. The simulated PV module array offers an output voltage of $208 \mathrm{~V}$, an output current of $2.48 \mathrm{~A}$ and an output power of $516 \mathrm{~W}$, and the irradiation level is adjustable by a rotary knob.

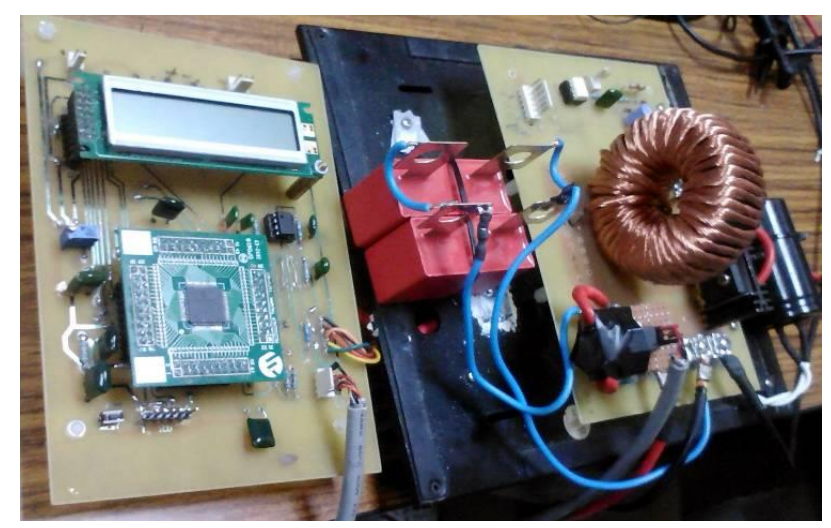

Figure 7. A photo of the implemented battery charger.

\subsubsection{Measured MPPT Performance}

Presented in Figure 8 is the measured performance of a constant voltage MPPT approach in response to an abrupt drop in solar radiation from 1000 to $600 \mathrm{~W} / \mathrm{m}^{2}$ at $\mathrm{t}=15 \mathrm{sec}$. and then an abrupt rise back to $1000 \mathrm{~W} / \mathrm{m}^{2}$. There is evidence that the output voltage of the PV module array is well regulated at a specified level by the presented MPP tracker against abrupt irradiation change.

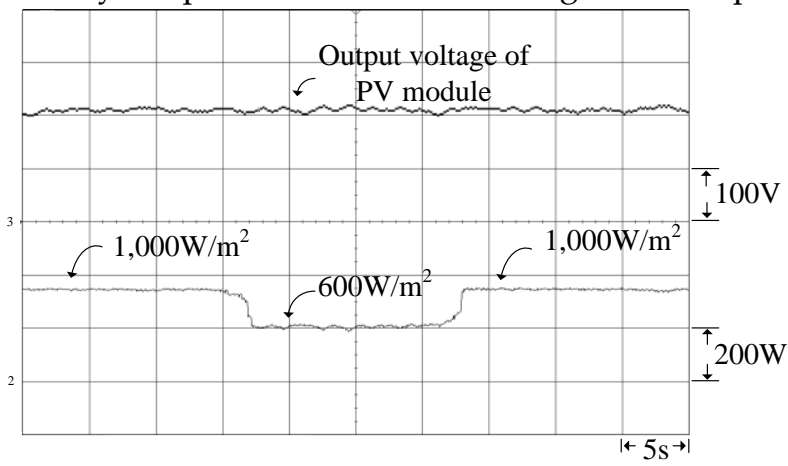


Figure 8. Well regulated output voltage of a PV module through a MPPT in response to an abrupt change in the amount of incident solar radiation.

The same experiment is repeated again for MPPT performance test except that the irradiation level rises from 400 to $800 \mathrm{~W} / \mathrm{m}^{2}$ and then plunges to $400 \mathrm{~W} / \mathrm{m}^{2}$. Just as in Figure 8 , the output voltage of the PV module array in Figure 9 is found to be well regulated again.

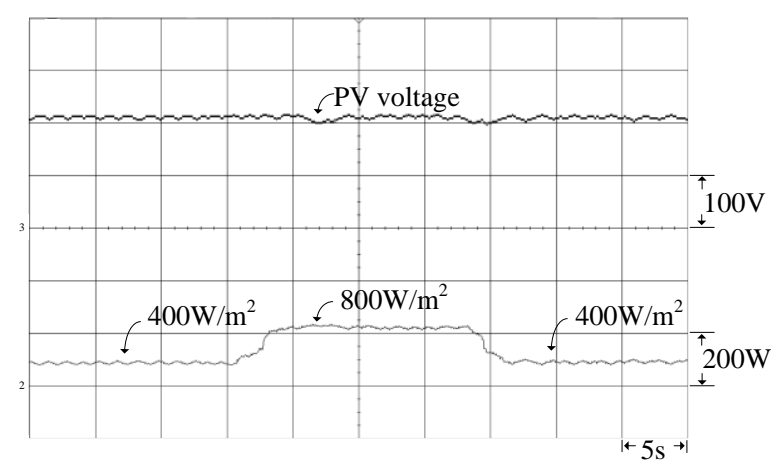

Figure 9. The same experiment as in Figure 8 is repeated except for a solar radiation change from 400 to 800 and then back to $400 \mathrm{~W} / \mathrm{m} 2$.

\subsubsection{Measured Battery Charger Performance}

Demonstrated in Figure 10 are the measured PWM and charge current waveforms. In the presence of sufficient solar radiation, the charge current can be regulated at $10 \mathrm{~A}$ by a skillful manipulation of the PWM duty cycle by means of a PIC18F8720 chip.

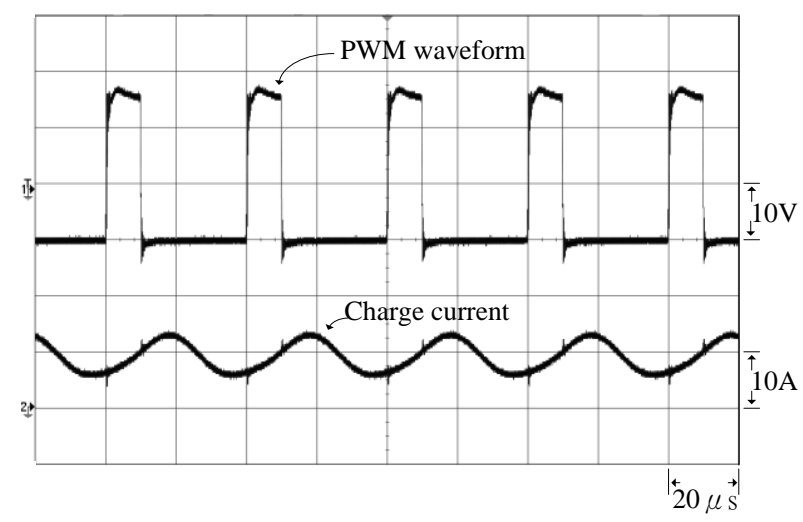

Figure 10. The measured PWM and charge current waveforms in constant current mode.

As can be found in Figure 11, the battery charger continues to operate in constant current mode until a voltage threshold of $58 \mathrm{~V}$ is reached. Subsequently, the battery charger works in constant voltage mode, the moment there is a charge current drop of approximately $0.01 \mathrm{C}$ amps.

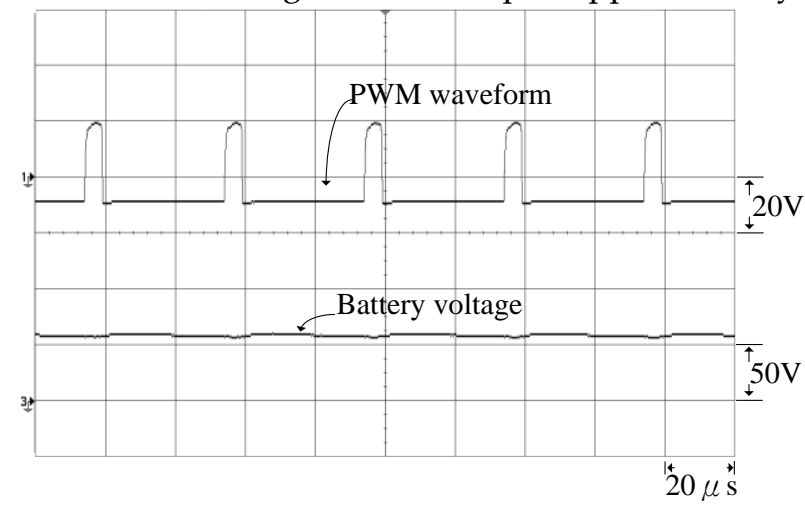


Figure 11. The measured PWM and battery voltage waveforms in constant voltage mode.

\subsubsection{High Current Charge/Discharge Characteristic}

For there is a non-uniform distribution of electrolyte in the interior of a Li-iron battery due to redox reaction, particularly during high current charge/discharge process, a battery measurement cannot be conducted until an equilibrium is reached. Illustrated in Figure 12 is a flow chart for the measurement of the battery charge/discharge characteristic curves. A fully discharged battery leads to a $0 \%$ SOC, and then stays idle for an hour. A two-stage charging strategy is performed subsequently, that is, the battery is firstly charged at a constant current of $1 \mathrm{C} \mathrm{amp} \mathrm{until} \mathrm{the} \mathrm{cut} \mathrm{off}$ voltage is reached. The battery charger is then operated in constant voltage mode till the charge current falls to $0.01 \mathrm{C}$ amps, a state treated as a $100 \%$ SOC. The battery remains idle for another hour, and then another battery discharge task is performed at a constant current of $1 \mathrm{C}$ amp. A TES-33 battery capacity tester [15], a product launched by the TES Electric Electronic Corp., Taiwan, is adopted to plot graphs of the battery voltage, current and SOC for understanding of battery behaviours over charge/discharge cycles.

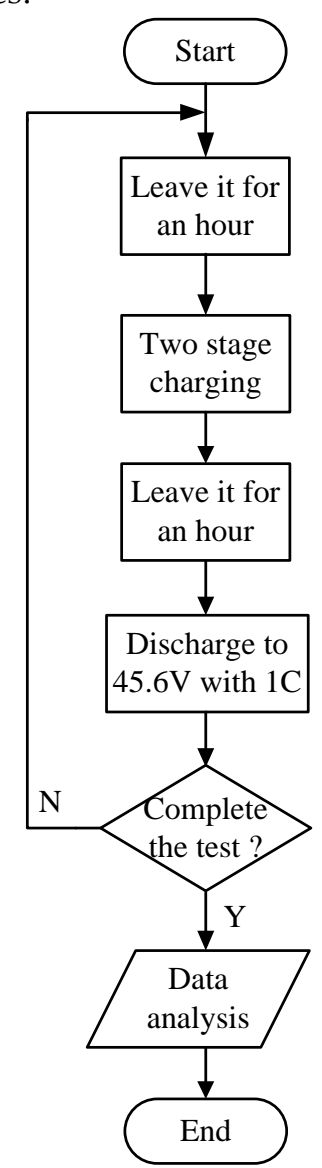

Figure 12. Flow chart of a battery charge/discharge cycle.

Provided in Figure 13 is a charging characteristic curve of an EA-480100-C15 Li-iron battery. It is found that the battery voltage rises rapidly at a constant charge current of $1 \mathrm{C}$ amp until a threshold of $53.29 \mathrm{~V}$ is reached, and then continues to increase linearly, but slowly, with time. In the constant current mode, the state of charge (SOC) rises linearly and rapidly as the battery voltage does. At a 1C amp charge current, it takes as short as 45.7 minutes to reach an $80.2 \% \mathrm{SOC}$, and the charger operation is switched to the constant voltage mode once a voltage threshold of $58.4 \mathrm{~V}$ is reached. Furthermore, it takes a time span of 64.8 minutes to reach a $90.1 \%$ SOC. The charge current plunges, once a cut off voltage of $58.4 \mathrm{~V}$ is reached, and the battery charger is operated in constant voltage mode. Hence, it is evident that the discharge timespan of an EA-480100-C15 Li-iron battery, as a solar energy storage device, can be reduced significantly. 


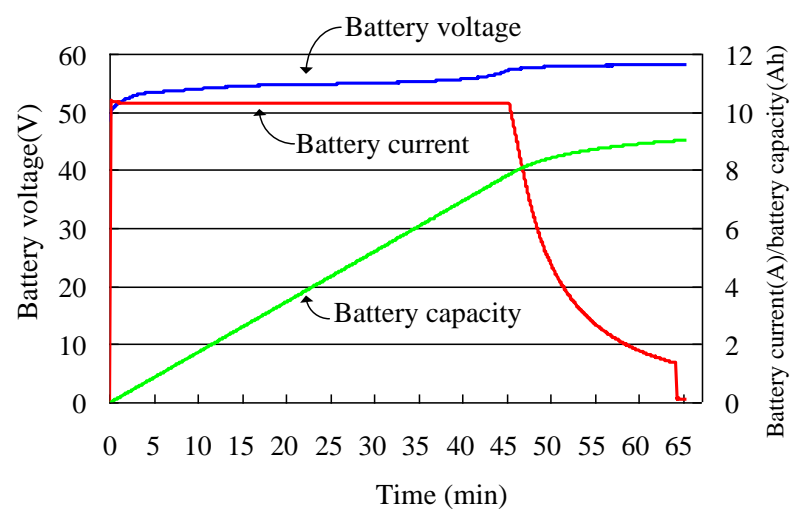

Figure 13. A two-stage charge characteristic curve for an EA-480100-C15 Li-iron battery at $1 \mathrm{C}$ amp in the constant current mode followed by the constant voltage mode.

Presented in Figure 14 is a plot of battery temperature against time at a charge current of $1 \mathrm{C}$ amp for an EA-480100-C15 Li-iron battery. In constant current mode, the temperature rises with time from 28.9 to $31.4^{\circ} \mathrm{C}$ until a voltage threshold is reached. Subsequently, the charger operation is switched to the constant voltage mode, and the battery temperature and particularly the charge current start to fall instantly in the meantime. A temperature rise lower than $3^{\circ} \mathrm{C}$ is seen in the battery charge process in Figure 14, eliminating the risk of overheating.

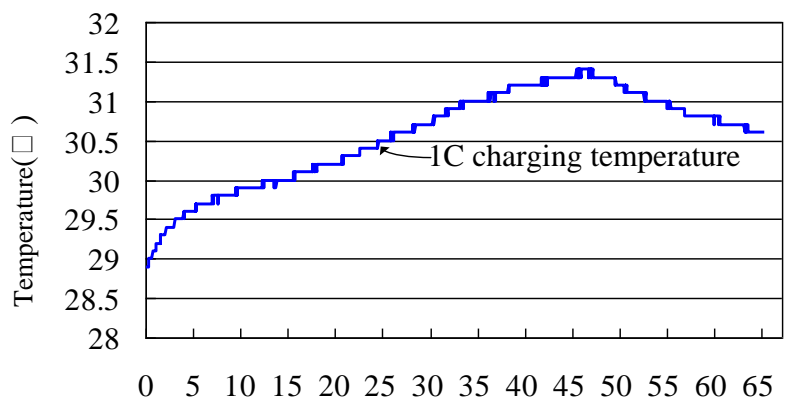

Time (min)

Figure 14. A plot of battery temperature versus time for the case in Figure 13.

Besides, provided in Figure 15 is a measured discharge characteristic curve of an EA-480100-C15 Li-iron battery at a discharge current of 1C amp. As indicated, it takes the battery 59 minutes or so to reach the cut-off voltage together with a $4.4 \%$ SOC, a finding in a good agreement with the specified $10 \mathrm{AH}$ battery capacity. The battery voltage decreases linearly with time from the initial 52.01 to $48.51 \mathrm{~V}$ together with an SOC of $11.86 \%$ over a time span of approximately 55 minutes. Subsequently, the battery voltage plunges to $45.63 \mathrm{~V}$, a voltage level treated as $0 \% \mathrm{SOC}$ herein. An average voltage of $48.82 \mathrm{~V}$ is seen over the entire discharge process, indicating the high performance of a Li-iron battery. 


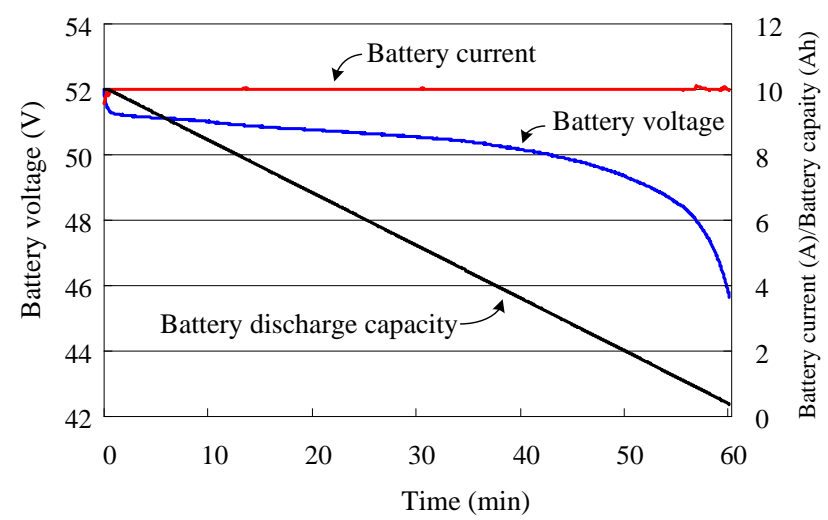

Figure 15. A discharge characteristic curve for an EA-480100-C15 Li-iron battery at 1C amp.

\section{Conclusions}

This paper presents an MPPT-based smart Li-iron battery charger, based on a Buck converter and implemented on a photovoltaic system. A constant voltage approach is employed to perform an MPP tracking task. Moreover, a two-stage battery charging strategy is adopted in this work, i.e. charging operation in constant current mode during the first stage of a charging process and then in constant voltage mode during the second stage. Consequently, a $\mathrm{LiFePO}_{4}$ battery is charged at a rapid pace at $1 \mathrm{C}$ amp, while an MPP tracker is enabled so as to deliver the maximum power to the battery in the event that the charge current falls below 1C amp. In contrast, the MPP tracker is disabled in case of a charge current beyond $1 \mathrm{C}$ amp. The battery charger continues to operate in constant current mode until a voltage threshold of $58 \mathrm{~V}$ is reached. At this point in time, the charger starts and then continues to operate in constant voltage mode until another voltage threshold of 58.4 $\mathrm{V}$ is reached. In this fashion, the presented two-stage high performance strategy is validated as an effective approach not merely to speed up the battery charging process, but also to protect batteries from overcharging.

\section{References}

1. Yang, S.H.; Tsai, T.C. Solar battery. Scientific Development 2005, Volume 309, 50-50.

2. Huang, Y.J. Study of Charge and Recharge Characteristics for LiFePO4 Lithium Rechargeable Battery. Master of Thesis, National Changhua University of Education, 2006.

3. Karamia, N.; Moubayedb, N.; Outbibc, R. General Review and Classification of Different MPPT Techniques. Renewable and Sustainable Energy Reviews 2017, Volume 68, 1-18.

4. Ezinwannea, O.; Zhongwena, F.; Zhijunb, L. Energy Performance and Cost Comparison of MPPT Techniques for Photovoltaics and Other Applications. Energy Procedia 2017, Volume 107, 297-303.

5. http://www.microchip.com.

6. "PIC18Fxx20 Data Sheet," Microchip Technology Inc. 2003. http://ww1.microchip.com/downloads/cn/DeviceDoc/cn011897.pdf.

7. Župa, T. ; Lišska, O. Charging Module for Newest Types of Rechargeable Batteries LiFePO4. IEEE $8^{\text {th }}$ International Symposium on Applied Machine Intelligence and Informatics (SAMI) 2010, 241-242.

8. Padhi, A. K. ; Nanjundaswamy, K. S.; Goodenough, J. B. Phospho-olivines as Positive-Electrode Materials for Rechargeable Lithium Batteries. The Electrochemical Society, Inc. J. Electrochem, Soc. 1997, Volume 144, No. 4, 1188-1194.

9. Padhi, A. K.; Nanjundaswamy, K. S. ; Masquelier, C.; Okada, S.; Goodenough, J. B. Effect of Structure on the $\mathrm{Fe}^{3+} / \mathrm{Fe}^{2+}$ Redox Couple in Iron Phosphates. The Electrochemical Society, Inc. J. Electrochem. Soc. 1997, Volume 144, No. 5, 1609-1613.

10. Masquelier, C. ; Padhi, A. K. ; Nanjundaswamy, K. S. ; Goodenough, J. B. New Cathode Materials for Rechargeable Lithium Batteries: The 3-D Framework Structures $\mathrm{Li}_{3} \mathrm{Fe}_{2}\left(\mathrm{XO}_{4}\right)_{3}(\mathrm{X}=\mathrm{P}, \mathrm{As})$. Journal of Solid State Chemistry 1998, Volume 135, No. 2, 228-234.

11. Stroe, D. I.; Swierczynski, M.; Stroe, A. I.; Kær, S. K. Generalized Characterization Methodology for Performance Modelling of Lithium-Ion Batteries. Batteries 2016, Volume 2, No.37, 1-20. 
12. Wang, S. C. Power Electronic, Tung Hua Booj Co. Ltd. 2001, ISBN13 : 9789576369131.

13. Kyocera Photovoltaic Module KC40T Specifications, Kyocera Solar Industries, May 2007.

14. PV Simulator-PVS0120 Specifications, http://www.kernel-sys.co.jp/product/PVsimulator.pdf.

15. http://www.tes.com.tw/33c.htm. 